\title{
Circ-HACEI Aggravates Cigarette Smoke Extract-Induced Injury in Human Bronchial Epithelial Cells via Regulating Toll-Like Receptor 4 by Sponging miR-485-3p
}

\section{Fujun Zhoul,* Cheng $\mathrm{CaO}^{2, *}$ Huiping Chai ${ }^{2}$ Jingfang $\mathrm{Hong}^{3}$ Min Zhu'}

'Department of Health and Nursing, Anhui Vocational College of City Management, Hefei City, Anhui Province, People's Republic of China; ${ }^{2}$ Department of Thoracic Surgery, 4th Affiliated Hospital of Anhui Medical University, Hefei City, Anhui Province, People's Republic of China; ${ }^{3}$ School of Nursing, Anhui Medical University, Hefei City, Anhui Province, People's Republic of China

*These authors contributed equally to this work
Correspondence: Cheng Cao Department of Thoracic Surgery, 4th Affiliated Hospital of Anhui Medical University, No. 100 Huaihai Avenue, Hefei, 230022, Anhui Province, People's Republic of China

$\mathrm{Tel} / \mathrm{Fax}+86$ 055I-6633I040

Email caochengaysfy@।63.com
Background: Smoking is the most common cause of chronic obstructive pulmonary disease (COPD), and the early diagnosis for COPD remains poor. Exploring the molecular mechanism and finding feasible biomarkers will be beneficial for clinical management of COPD. Circular RNAs (circRNAs) are noncoding RNAs that act as miRNA sponges to regulate the expression levels of genes, leading to the changes of cellular phenotypes and disease progression. CircRNA HECT domain and ankyrin repeat containing E3 ubiquitin protein ligase 1 (circ-HACE1) was abnormally expressed after the induction of cigarette smoke extract (CSE) in cell model. This study was performed to explore its function and mechanism in COPD.

Methods: Circ-HACE1, microRNA-485-3p (miR-485-3p) and toll-like receptor 4 (TLR4) detection was performed by quantitative real-time polymerase chain reaction (qRT-PCR). Cell viability and apoptosis/cell cycle were respectively examined using cell counting kit-8 (CCK-8) and flow cytometry. Inflammatory cytokines were determined by enzyme-linked immunosorbent assay (ELISA). Oxidative stress was evaluated through the measurement of malondialdehyde (MDA) and superoxide dismutase (SOD). The target binding analysis was conducted via dualluciferase reporter assay. Western blot was employed for protein expression detection of TLR4. Results: Circ-HACE1 was overexpressed in smokers or smokers with COPD and CSE upregulated circ-HACE1 expression in 16HBE cells. Knockdown of circ-HACE1 attenuated CSE-stimulated cell viability and cell cycle repression, as well as the enhancement of cell apoptosis, inflammatory response and oxidative stress. MiR-485-3p was a target of circHACE1. Circ-HACE1 regulated CSE-induced cell injury via targeting miR-485-3p. TLR4 was a downstream target of miR-485-3p, and miR-485-3p inhibited the CSE-induced cell damages by directly downregulating the level of TLR4. Circ-HACE1/miR-485-3p regulated TLR4 expression in CSE-treated 16HBE cells, and TLR4 overexpression also reversed all effects of si-circ-HACE1 on CSE-treated 16HBE cells.

Conclusion: These findings elucidated that circ-HACE1 contributed to the CSE-induced cell damages in COPD cell models via regulating TLR4 by acting as the sponge of miR-485-3p.

Keywords: circ-HACE1, chronic obstructive pulmonary disease, cigarette smoke extract, miR-485-3p, TLR4

\section{Introduction}

Chronic obstructive pulmonary disease (COPD) is an inflammatory disease in the respiratory system with airflow limitation and pulmonary dysfunction. ${ }^{1}$ Cigarette smoke can cause airway inflammation in COPD, which is progressive and 
irreversible after smoking cessation. ${ }^{2,3}$ COPD remains under-diagnosed and under-treated until now, particularly for those mild and moderate patients. ${ }^{4}$ Exploring promising biomarkers of COPD progression may improve the treatment for early COPD. ${ }^{4}$

COPD has been found to be linked to dysregulated expression of noncoding RNAs (ncRNAs), including circular RNAs (circRNAs), long noncoding RNAs (lncRNAs) and microRNAs (miRNAs). ${ }^{5}$ CircRNAs are covalently closed loops different from those linear RNAs and function as gene regulators in mammals via the sponge effects on microRNAs (miRNAs). ${ }^{6}$ Disease progression in human life is largely affected by circRNAs. ${ }^{7,8}$ CircRNA HECT domain and ankyrin repeat containing E3 ubiquitin protein ligase 1 (circ-HACE1, hsa_circ_0077520) was shown to be upregulated in cigarette smoke extract (CSE)-induced COPD cell model, ${ }^{9}$ but its function and underlying mechanism in COPD are still unclear.

Regulatory miRNAs are also tractable makers for the diagnosis and treatment of COPD. ${ }^{10,11}$ By binding to the $3^{\prime}$ untranslated regions (3'-UTRs) of messenger RNAs (mRNAs), miRNAs can modulate the expression of target genes. ${ }^{12}$ The miRNA expression profiles in the previous study have indicated that microRNA-485-3p (miR-485-3p) was downregulated in patients with COPD. ${ }^{13}$ However, it is unknown what role miR-485-3p plays in COPD and whether it can be used as a miRNA target of circ-HACE1. In addition, CSE upregulated the expression of toll-like receptor 4 (TLR4) in THP-1 cells and miR-149-3p targeted TLR4 to downregulate its level. ${ }^{14} \mathrm{Jia}$ et al also reported that miR-497 repressed inflammatory response via targeting TLR4 in CSEtreated human bronchial epithelial (HBE) cells. ${ }^{15}$ The potential of TLR4 as a target of miR-485-3p needs to be explored.

Currently, the effects of circ-HACE1 and miR-485-3p on CSE-stimulated cell damage were investigated. Moreover, the regulation of circ-HACE1 on TLR4 via targeting miR-485-3p was verified.

\section{Materials and Methods}

\section{Blood Samples and Serum Preparation}

This study was approved by the Ethics Committee of 4th Affiliated Hospital of Anhui Medical University and performed following the Declaration of Helsinki. The whole blood samples were collected from non-smokers, smokers and smokers with COPD ( $\mathrm{n}=24$ per group) at the 4th Affiliated Hospital of Anhui Medical University. All blood samples were centrifuged at $1200 \times \mathrm{g}$ at room temperature for $10 \mathrm{~min}$, and the supernatant sera were saved in liquid nitrogen before RNA extraction. All subjects have signed the written informed consent forms for sample use in this research. The demographic and clinicopathological characteristics of these subjects are shown in Table 1.

\section{Preparation of CSE}

CSE was prepared as previously reported. ${ }^{16}$ Briefly, four commercial cigarettes were combusted with a constant speed vacuum pump and the burning time of each cigarette was controlled to $5 \mathrm{~min}$. Five hundred-milliliter smoke was bubbled into a flask with 25-mL Roswell Park Memorial Institute-1640 (RPMI-1640) medium that was pre-warmed at $37^{\circ} \mathrm{C}$. The suspension was titrated to $\mathrm{pH} 7.4$ and filtered through a $0.22-\mu \mathrm{m}$ filter (Millipore, Bedford, MA, USA) to remove large particles. The solution was sterilized and the optical density (OD) was determined. CSE was qualified when $\triangle \mathrm{OD}$ (A320-A540) was between 0.9 and 1.2. The final solution was considered as $100 \%$ CSE. One hundred percent CSE was diluted with serum-free cell medium to $1 \%, 2 \%$ and $4 \%$ working concentrations.

\section{Cell Culture and Treatment}

Human bronchial epithelial cell line 16HBE (SigmaAldrich, St. Louis, MO, USA) was cultured in RPMI-1640 medium (Sigma-Aldrich) supplemented with $10 \%$ fetal bovine serum (FBS; Gibco, Carlsbad, CA, USA) and 100

Table I Demographic and Clinicopathological Characteristics of the Subjects in This Study

\begin{tabular}{|l|l|l|l|}
\hline Parameters & $\begin{array}{l}\text { Non- } \\
\text { Smokers } \\
(\mathbf{n}=17)\end{array}$ & $\begin{array}{l}\text { Smokers } \\
(\mathbf{n}=\mathbf{2} \text { I) }\end{array}$ & $\begin{array}{l}\text { Smokers with } \\
\text { COPD } \\
(\mathbf{n}=\mathbf{2 4})\end{array}$ \\
\hline $\begin{array}{l}\text { Gender (male/ } \\
\text { female) }\end{array}$ & $17 / 0$ & $21 / 0$ & $24 / 0$ \\
\hline Age (years) & $59.6 \pm 4.5$ & $61.5 \pm 6.8$ & $63.2 \pm 7.9$ \\
\hline $\begin{array}{l}\text { Smoking history } \\
\text { (pack-years) }\end{array}$ & 0 & $44.3 \pm 5.8$ & $49.6 \pm 6.5$ \\
\hline BMI (kg/m $\left.{ }^{2}\right)$ & $24.8 \pm 3.2$ & $29.3 \pm 3.9$ & $29.8 \pm 4.1$ \\
\hline FEV (L) & $3.32 \pm 0.28$ & $2.91 \pm 0.23$ & $2.08 \pm 0.15$ \\
\hline FVC (L) & $4.21 \pm 0.21$ & $3.62 \pm 0.33$ & $3.36 \pm 0.31$ \\
\hline FEV /FVC\% & $77.2 \pm 2.1$ & $82.1 \pm 2.5$ & $62.1 \pm 1.9$ \\
\hline FEV (\% predicted) & $98.3 \pm 4.5$ & $90.2 \pm 6.2$ & $62.1 \pm 3.9$ \\
\hline
\end{tabular}

Abbreviations: COPD, chronic obstructive pulmonary disease; BMI, body mass index; FVC, forced vital capacity; $\mathrm{FEV}_{1}$, forced expiratory volume in one second. 
$\mathrm{U} / \mathrm{mL}$ penicillin and $100 \mu \mathrm{g} / \mathrm{mL}$ streptomycin (Gibco) in a $5 \% \mathrm{CO}_{2}$ incubator at $37^{\circ} \mathrm{C} .16 \mathrm{HBE}$ cells were treated with the different concentrations of CSE within $30 \mathrm{~min}$ after dilution and cell collection was performed after $24 \mathrm{~h}$.

\section{Cell Transfection}

The sequences of circ-HACE1 and TLR4 were inserted into pCE-RB-Mam vector (RIBOBIO, Guangzhou, China) and pcDNA vector (Invitrogen, Carlsbad, CA, USA), respectively. The recombinant vectors pCE-RB-Mam-circHACE1 and pcDNA-TLR4 were named as circ-HACE1 and TLR4. The used oligonucleotides (RIBOBIO) are listed in Table 2. 16HBE cells were treated with $2 \%$ CSE for $24 \mathrm{~h}$ and transfected with oligonucleotides or vectors using Lipofectamine ${ }^{\mathrm{TM}} 3000$ (Invitrogen), referring to the transfection steps provided by manufacturer.

\section{The Quantitative Real-Time Polymerase Chain Reaction (qRT-PCR)}

Total RNA was isolated from serum samples and cells by TRIzol Reagent (Invitrogen), then $2 \mu \mathrm{g}$ RNA was applied for synthesizing the complementary DNA (cDNA) by ReverTra Ace ${ }^{\circledR}$ qPCR RT Kit (Toyobo, Kita-Ku, Osaka, Japan). The qRT-PCR was performed through the reaction system by cDNA, primers and SYBR $^{\circledR}$ Green Realtime PCR Master Mix (Toyobo) on the ABI PRISM ${ }^{\circledR} 7000$ Sequence Detection System (Applied Biosystems, Foster City, CA, USA). The primer sequences for each molecule were as follows: forward (F), 5'-GACCTTGTGCAGCATGTCAG-3' and reverse (R), 5'-AGCAAAACCAAGCATTCCAC-3' for circ-HACE1; F, 5'-GGTGTACTGTAGGTGGTCGG-3' and R, 5'-AGAGCCCTACATCTCGCCTG-3' for HACE1; F, 5'GCCGAGGTCATACACGGCTCTCCTCT-3' and R, 5'TGTCGTGGAGTCGGCAATTC-3' for miR-485-3p; F, 5'-G

Table 2 The Used Oligonucleotides for Cell Transfection

\begin{tabular}{|l|l|}
\hline Abbreviations & Expansions \\
\hline si-circ-HACEI & Small interfering RNA against circ-HACEI \\
\hline si-NC & Small interfering RNA negative control \\
\hline miR-485-3p & miRNA mimic for miR-485-3p \\
\hline miR-NC & miRNA mimic negative control \\
\hline anti-miR-485-3p & miRNA inhibitor for miR-485-3p \\
\hline anti-miR-NC & miRNA inhibitor negative control \\
\hline
\end{tabular}

GCCATTGCTGCCAACAT-3' and R, 5'-CA ACAATCACCTTTCGGCTTTT-3' for TLR4; 5'-A TTCCATGGCACCGTCAAGGCTGA-3' and R, 5'TTCTCCATGGTGGTGAAGACGCCA-3' for glyceraldehyde-phosphate dehydrogenase (GAPDH); 5'-CTCGCTTC GGCAGCACA-3' and R, 5'-AACGCTTCACGAATT TGCGT-3' for U6. The internal controls GAPDH and U6 were used for expression standardization. The $2^{-\Delta \Delta \mathrm{Ct}}$ method was adopted in this study for data analysis.

\section{Identification of circRNA}

12 U Ribonuclease R (RNase R; Epicentre Technologies, Madison, WI, USA) was added to $3 \mu \mathrm{g}$ total RNA for 60 min at $37^{\circ} \mathrm{C}$ and the stability of circ-HACE1 was assessed by qRT-PCR detection compared with linear HACE1 expression. In addition, the location of circ-HACE1 in 16HBE cells was analyzed by qRT-PCR after nuclear and cytoplastic RNA extraction using PARISTM Kit (Invitrogen), with U6 and GAPDH as the respective control for nucleus and cytoplasm.

\section{Cell Counting Kit-8 (CCK-8) Assay}

After CSE treatment for $24 \mathrm{~h}$ or transfection for $48 \mathrm{~h}$ in 16HBE cells, $10 \mu \mathrm{L}$ CCK-8 solution (Sigma-Aldrich) was pipetted to cells for $4 \mathrm{~h}$-incubation. The viable cell number can be quantitated through the absorbance $(450 \mathrm{~nm})$ detection under the microplate reader (Bio-Rad, Hercules, CA, USA).

\section{Flow Cytometry}

For cell apoptosis, $1 \times 10^{5}$ harvested $16 \mathrm{HBE}$ cells were stained by Annexin V-fluorescein isothiocyanate (FITC) and propidium iodide (PI) via Annexin V-FITC Apoptosis Detection Kit (BD Biosciences, San Diego, CA, USA) as per the manufacturer's guidelines. After cell determination via the flow cytometer (BD Biosciences), we can distinguish the apoptotic cells (Annexin V+/PI-, Annexin $\mathrm{V}+/ \mathrm{PI}+$ ) from the viable cells. The apoptotic rate was calculated using the formula: apoptotic cells/total cells $\times 100 \%$. For cell cycle, $5 \times 10^{5}$ cells were incubated with ethanol (Sigma-Aldrich) and stained with PI according to the specification of Cell Cycle Assay Kit (Dojindo, Kumamoto, Japan), followed by the detection under the flow cytometer.

\section{Enzyme-Linked Immunosorbent Assay (ELISA)}

Inflammatory response was assessed through detecting the common inflammatory cytokines levels via ELISA. The 
examination of interleukin-1beta (IL-1 $\beta$ ) in cell culture supernatant and tumor necrosis factor-alpha (TNF- $\alpha$ ) in cell lysate was performed using Human IL-1 $\beta$ ELISA Kit and Human TNF-alpha ELISA Kit (Sigma-Aldrich), respectively.

\section{Detection of Malondialdehyde (MDA) and Superoxide Dismutase (SOD)}

To evaluate oxidative stress in $16 \mathrm{HBE}$ cells, MDA and SOD levels were examined by Lipid Peroxidation (MDA) Assay Kit and SOD Assay Kit (Sigma-Aldrich) in accordance with the appendant instruction books.

\section{Dual-Luciferase Reporter Assay}

The bioinformatics analysis in this study was completed using online Circinteractome and Targetscan. The sequences of circ-HACE1 and TLR4 3'UTR that harbored the miR-485$3 p$ binding sites were respectively cloned into the luciferase expression vector pmirGLO (Promega, Madison, WI, USA) to obtain the wild-type (WT) plasmids WT-circ-HACE1 and TLR4 3'UTR-WT. The mutant-type (MUT) plasmids MUTcirc-HACE1 and TLR4 3'UTR-MUT were also formed after circ-HACE1 and TLR4 3'UTR sequences were mutated in the binding sites for miR-485-3p. The abbreviations of these constructs are shown in Table 3. Each construct was transfected into $16 \mathrm{HBE}$ cells along with miR-485-3p or miR-NC, followed by the measurement of relative luciferase activity through the Dual-Luciferase Reporter Assay System (Promega).

\section{Western Blot}

Protein isolation in $16 \mathrm{HBE}$ cells was carried out by radioimmunoprecipitation assay (RIPA) buffer (Sigma-Aldrich), followed by the separation of equal proteins $(40 \mu \mathrm{g})$ via sodium dodecyl sulfate-polyacrylamide gel electrophoresis (SDS-PAGE). After protein transferring onto the polyvinylidene difluoride (PVDF) membranes (Millipore) and nonspecific binding prevention in 5\% skim milk (Invitrogen),

Table 3 The Abbreviations of Constructs in Dual-Luciferase Reporter Assay

\begin{tabular}{|l|l|}
\hline Abbreviations & Expansions \\
\hline WT-circ-HACEI & pmirGLO-circ-HACEI of wild type \\
\hline MUT-circ-HACEI & pmirGLO-circ-HACEI of mutant type \\
\hline TLR4 3'UTR-WT & pmirGLO-TLR4 3'UTR of wild type \\
\hline TLR4 3'UTR-MUT & pmirGLO-TLR4 3'UTR of mutant type \\
\hline
\end{tabular}

PVDF membranes were incubated with anti-TLR4 (Abcam, Cambridge, UK, ab13556, 1:500) or reference gene antiGAPDH (Abcam, ab181603, 1:10,000) at $4^{\circ} \mathrm{C}$ overnight and Goat Anti-Rabbit IgG H\&L secondary antibody (Abcam, ab205718, 1:3000) at $25^{\circ} \mathrm{C}$ for $1 \mathrm{~h}$. The bands of proteins were shown by enhanced chemiluminescence (ECL) Western HRP Substrate (Millipore). Image Lab software (Bio-Rad) was used to analyze the grey level of each band.

\section{Statistical Analysis}

Pearson's correlation coefficient was exploited for analyzing the linear relation. Data expressed as the mean \pm standard deviation (SD) were analyzed via SPSS 24.0. For difference analysis, Student $t$-test and one-way analysis of variance (ANOVA) followed by Tukey's test were respectively performed to compare the difference of two groups and multiple groups. $P<0.05$ represented a significant level in statistical difference.

\section{Results}

\section{Upregulation of Circ-HACEI Was Found in Smokers or Smokers with COPD and CSE-Treated I6HBE Cells}

Firstly, we analyzed the expression level of circ-HACE1 in serum samples from three groups. As shown in Figure 1A, circ-HACE1 was upregulated in smokers compared to Non-smokers and its level was higher in smokers with COPD than Non-smokers or smokers. The non-toxic level of CSE was tested by treatment of $0.2 \%$ CSE, $0.4 \% \mathrm{CSE}$ or $0.6 \% \mathrm{CSE}$ in $16 \mathrm{HBE}$ cells. The results indicated that no significance of cell viability was detected in three groups and we defined the non-toxic level of CSE was $0.6 \%$ (Supplementary Figure 1A). Circ-HACE1 level was increased in $0.6 \%$ CSE group, but the difference was not quite significant (Supplementary Figure 1B). Furthermore, the expression of circ-HACE1 was determined after higher concentrations of CSE treatment. As shown in Figure 1B, circ-HACE1 was elevated by different concentrations of $\mathrm{CSE}(1 \%, 2 \%, 4 \%)$ in a dosedependent way. $2 \%$ CSE was used in the subsequent assays. RNase R treatment significantly reduced HACE1 level but had no notable effect on circ-HACE1 expression (Figure 1C), suggesting the high stability of circ-HACE1 relative to its linear form. Through the expression comparison with nuclear U6 and cytoplastic GAPDH, we identified that circ-HACE1 was localized in the cytoplasm of $16 \mathrm{HBE}$ cells (Figure 1D). Smoke induced the upregulation of circ-HACE1 in COPD patients and 16HBE cells. 

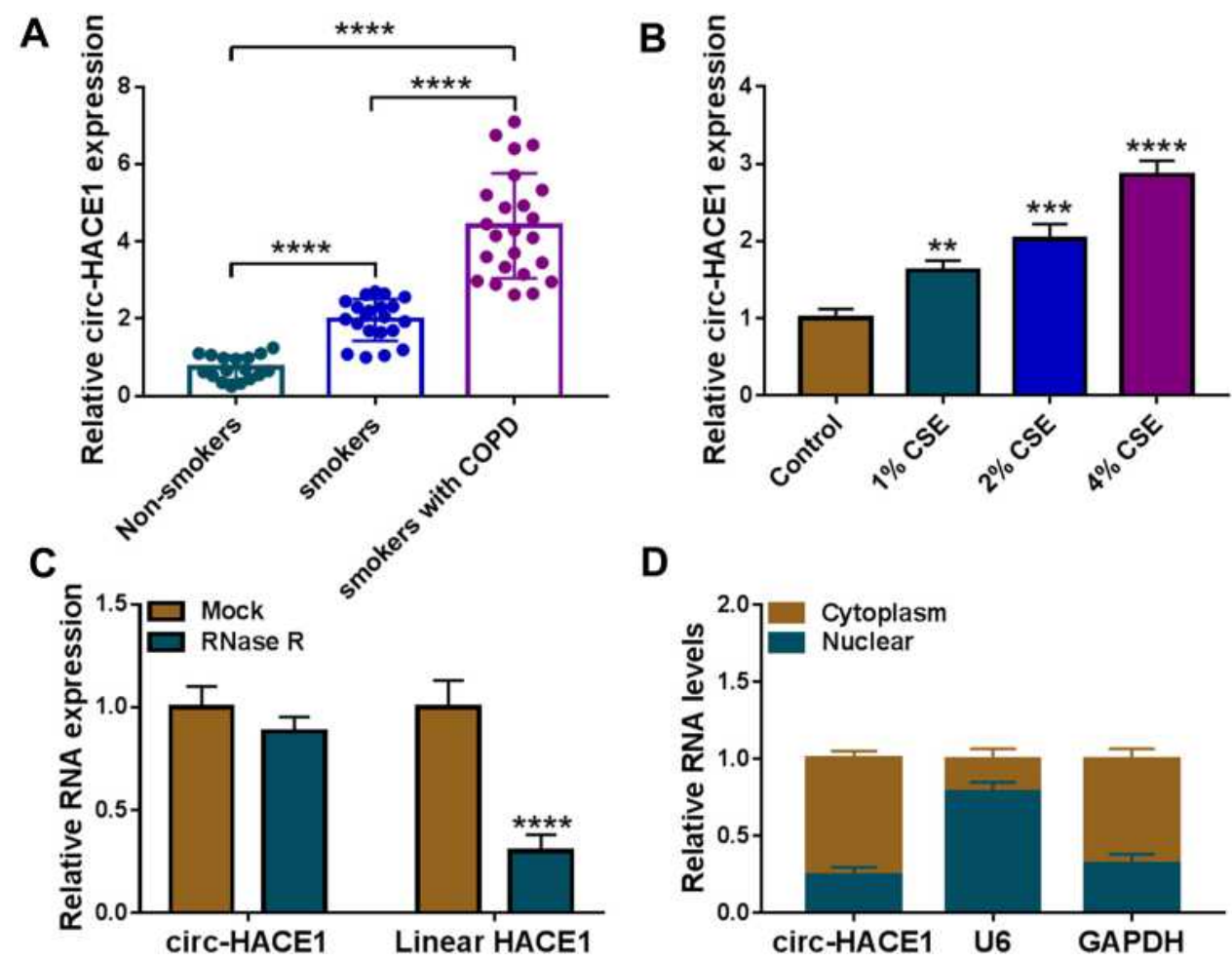

Figure I Upregulation of circ-HACEI was found in smokers or smokers with COPD and CSE-treated I6HBE cells. (A) The qRT-PCR analysis was conducted to determine the expression of circ-HACEI in serum samples from Non-smokers, smokers and smokers with COPD. The expression of circ-HACEI in Non-smokers group was set as I, and that in smokers and smokers with COPD groups were relative to Non-smoker group. (B) Circ-HACEI level was detected using qRT-PCR after I6HBE cells treated with I\% CSE, $2 \%$ CSE or 4\% CSE. The circ-HACEI level in control group was set as I, and that in three CSE treatment groups was compared to the control group. (C) The levels of circ-HACEI and linear HACEI were assayed by qRT-PCR after RNase R treatment in total RNA. RNA expression in Mock group was set as I, and that in RNase R group was compared with Mock group. (D) Circ-HACEI, U6 and GAPDH expression detection was performed by qRT-PCR after RNA isolation from cytoplasm and nucleus of I $6 \mathrm{HBE}$ cells. $* * P<0.01$, $* * * P<0.001$, $* * * * P<0.0001$

\section{CSE-Induced Cell Viability Reduction, Apoptosis Acceleration, Inflammatory and Oxidative Injuries Were Attenuated After Knockdown of Circ-HACEI in I6HBE Cells}

CSE-treated 16HBE cells were transfected with si-circHACE1, and the qRT-PCR results indicated that transfection of si-circ-HACE1 had great interfering efficiency to abolish the CSE-mediated circ-HACE1 upregulation contraposed to transfection of si-NC (Figure 2A). CCK-8 assay revealed that cell viability was inhibited by CSE in a dose-dependent way (Figure 2B) while the inhibition was countervailed by si-circ-HACE1 (Figure 2C). The analysis of apoptosis and cell cycle by flow cytometry demonstrated that the promotion of cell apoptosis (Figure 2D) and inhibition of cell cycle progression (Figure 2E) by CSE were offset after circ-HACE1 expression downregulation. The detection of inflammatory cytokines (IL-1 $\beta$ and TNF- $\alpha$ ) by ELISA also showed that knockdown of circHACE1 abolished the stimulative influences of CSE on inflammatory response (Figure 2F). Oxidative stress is a peroxidation which can increase MDA and decrease SOD, with fundamental association in diverse diseases. ${ }^{17,18}$ MDA upregulation (Figure 2G) and SOD downregulation (Figure $2 \mathrm{H}$ ) were triggered by CSE in $16 \mathrm{HBE}$ cells contrast to control cells, while this oxidative stress was reverted when CSE-treated cells were transfected with si-circ-HACE1. CSE-induced cell injury was returned by repressing circ-HACE1 expression.

\section{Circ-HACEI Regulated miR-485-3p as}

\section{a Sponge}

In the Circinteractome software, circ-HACE1 was predicted to have the binding sites of miR-485-3p (Figure 3A). Then, we performed the dual-luciferase reporter assay to prove the combination between circ-HACE1 and miR-485-3p. As Figure 3B displayed, luciferase signal inhibition was observed in WT-circ-HACE1 group rather than MUT-circHACE1 group after miR-485-3p transfection in 16HBE cells (relative to miR-NC transfection). The expression of miR485-3p was downregulated in serum samples from smokers or smokers with COPD by contrast with serum samples 
A

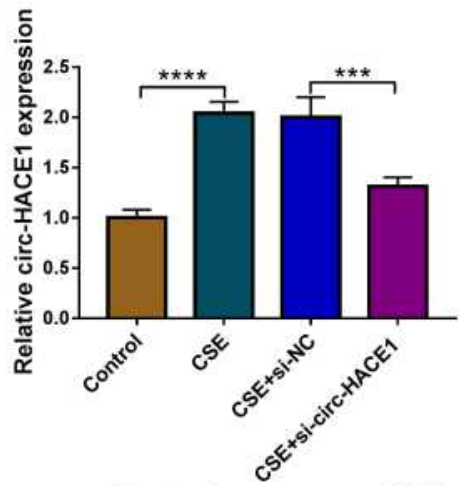

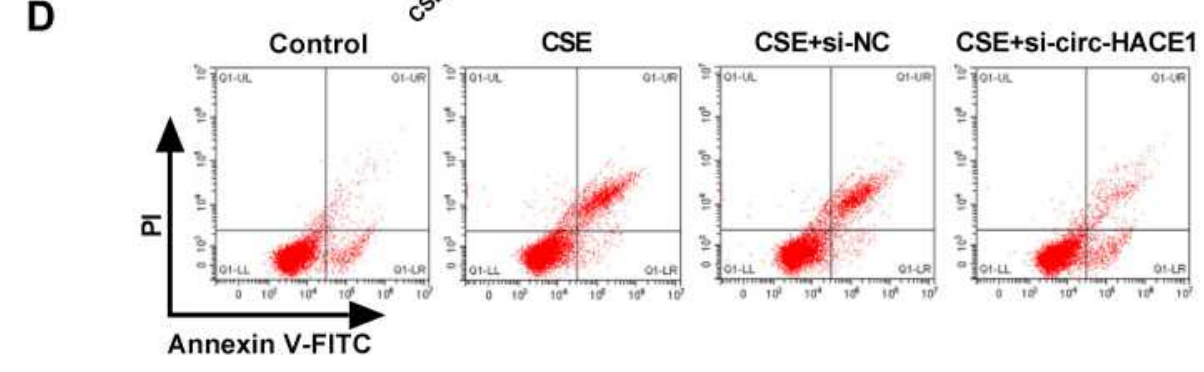

B

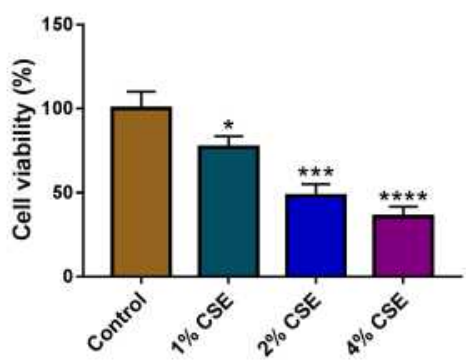

C

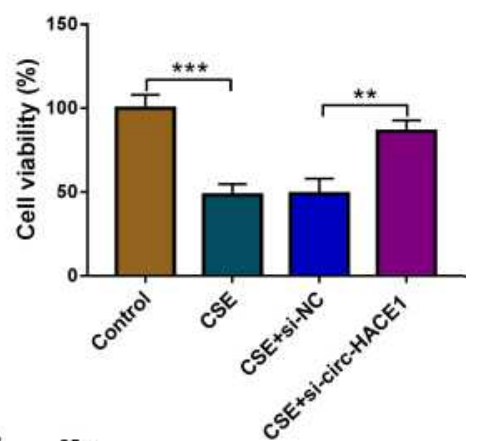

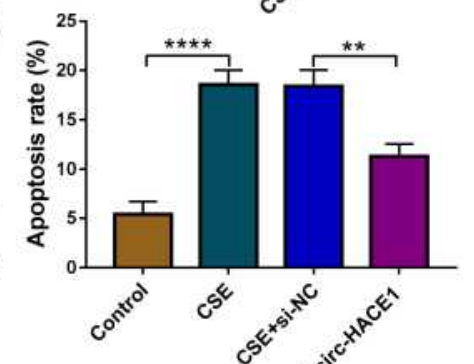

E

Control

CSE

CSE+Si-NC

CSE+si-circ-HACE1

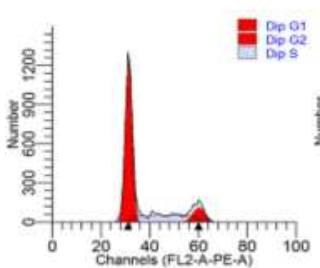

$\mathbf{F}$

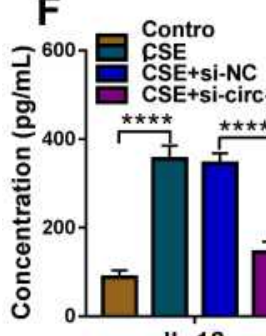

IL-1 $\beta$

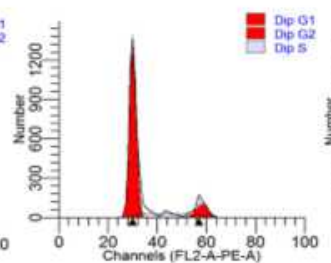

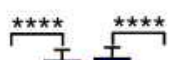

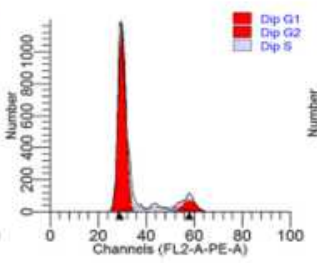

G

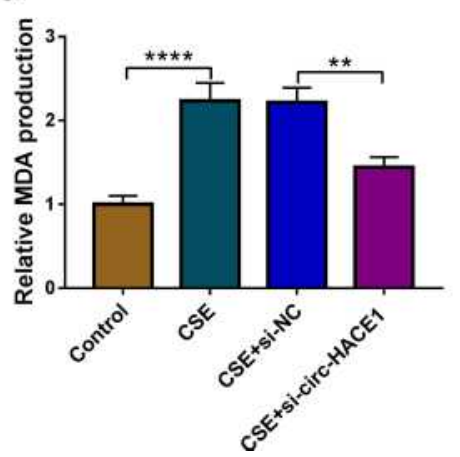

H
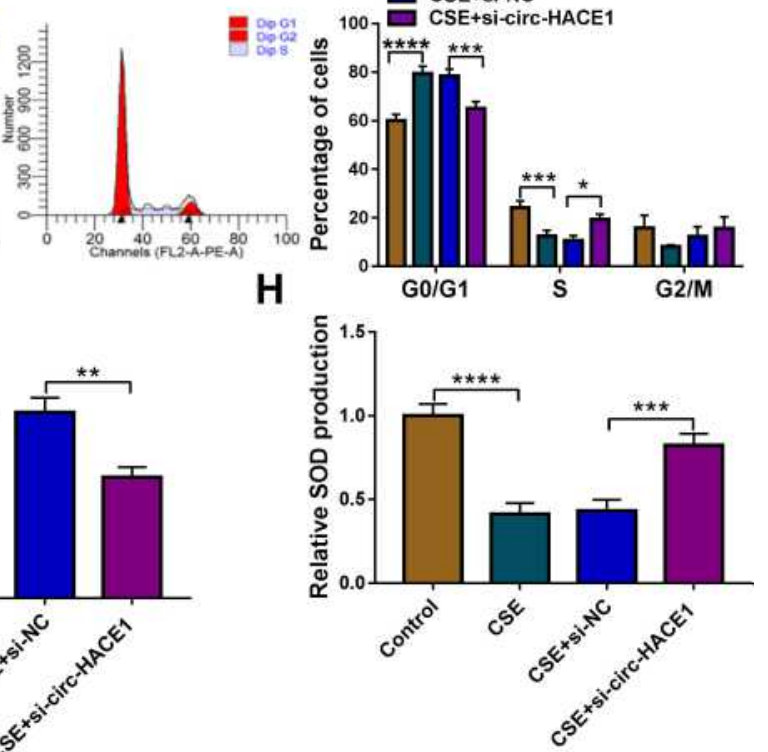

Figure 2 CSE-induced cell viability reduction, apoptosis acceleration, inflammatory and oxidative injuries were attenuated after knockdown of circ-HACEI in I6HBE cells. (A) The expression of circ-HACEI was examined using qRT-PCR after $16 \mathrm{HBE}$ cells were treated with $2 \%$ CSE and transfected with si-NC or si-circ-HACEI. The circHACEI level in other three groups was compared to the control group (set as I). (B) CCK-8 was carried out for cell viability analysis after CSE treatment with different concentrations (I\%, $2 \%, 4 \%)$ in $16 \mathrm{HBE}$ cells. (C) Cell viability detection was performed by CCK-8 assay in control, $2 \%$ CSE, $2 \%$ CSE+si-NC or $2 \%$ CSE+si-circ-HACEI groups. (D and E) Flow cytometry was used to assess cell apoptosis (D) and cell cycle progression (E) in control, $2 \%$ CSE, $2 \%$ CSE+si-NC or $2 \%$ CSE+si-circ-HACEI groups. (F) ELISA was performed to measure the levels of IL-I $\beta$ and TNF- $\alpha$ in control, $2 \%$ CSE, $2 \%$ CSE+si-NC or $2 \%$ CSE+si-circ-HACEI groups. (G and H) MDA and SOD levels were determined for the evaluation of oxidative stress in control, $2 \%$ CSE, $2 \%$ CSE+si-NC or $2 \%$ CSE+si-circ-HACEI groups. The relative production of MDA or SOD in each treatment group was compared to the control group (set as I). $* P<0.05$, $* * P<0.01$, $* * * P<0.001$, $* * * * P<0.0001$.

from non-smokers (Figure 3C). The same downregulation of miR-485-3p was detected in $16 \mathrm{HBE}$ cells after $1 \%, 2 \%$ or $4 \%$ CSE treatment relative to the control group (Figure 3D). After the linear analysis by Pearson's correlation coefficient, a negative relationship $(r=-0.7632, p<0.001)$ was found between circ-HACE1 and miR-485-3p expression (Figure $3 \mathrm{E})$. The level of circ-HACE1 of CSE+circ-HACE1 group was higher than that of CSE-alone group in 16HBE cells (Figure $3 \mathrm{~F}$ ), showing the successful overexpression of circHACE1 vector. In CSE-treated 16HBE cells, miR-485-3p 
A
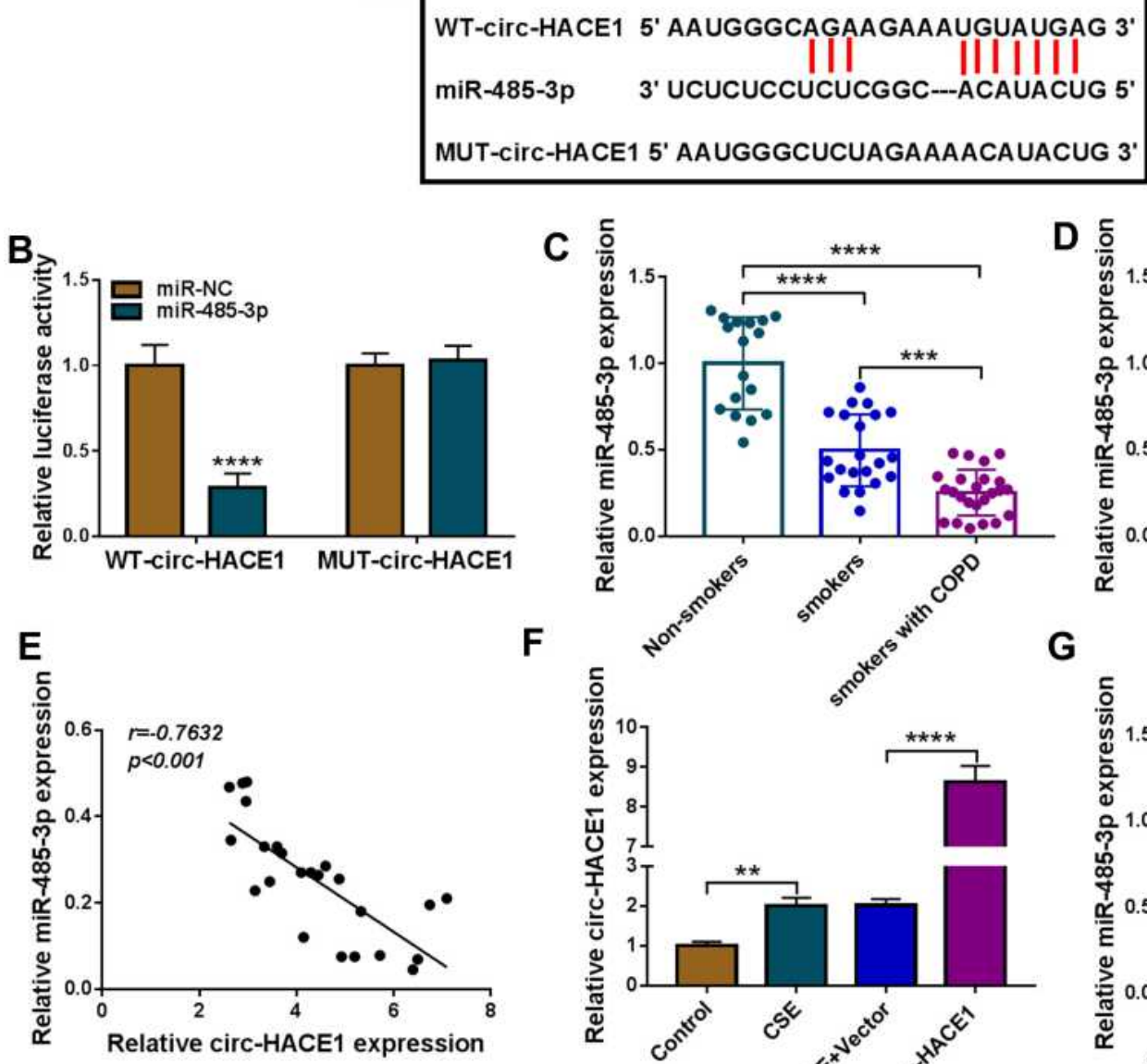

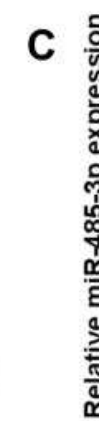

$\mathbf{F}$

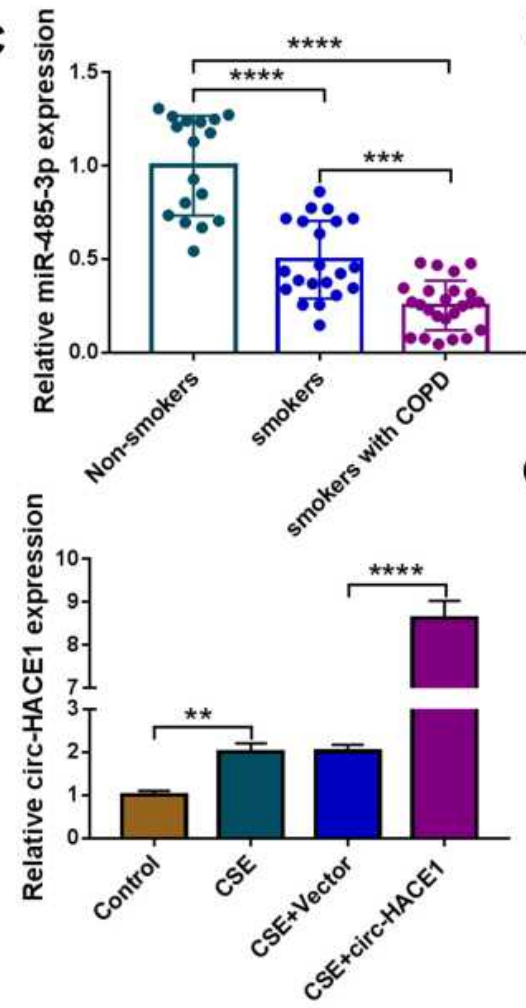

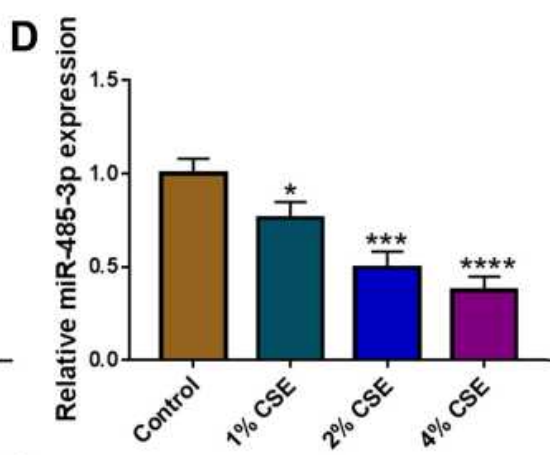

G

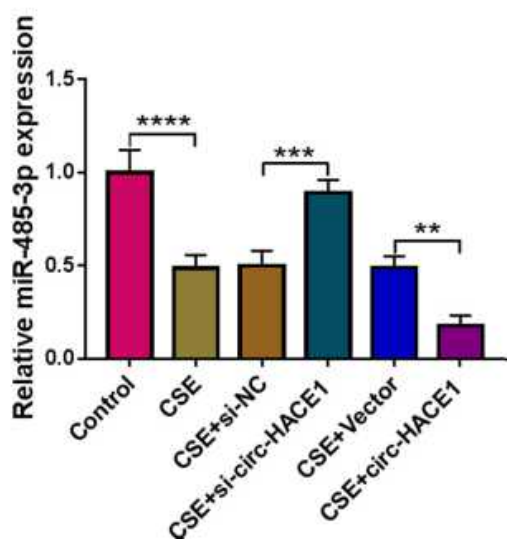

Figure 3 Circ-HACEI regulated miR-485-3p as a sponge. (A) The Circinteractome software was applied to analyze the binding sites between circ-HACEI and miR-485-3p sequences. (B) Dual-luciferase reporter assay was administrated for binding analysis between circ-HACEI and miR-485-3p. (C and D) The qRT-PCR was used for miR-485$3 p$ expression analysis in serum samples (C) and 1\%, $2 \%$ or $4 \%$ CSE-treated 16 HBE cells (D). The miR-485-3p expression in smokers/smokers with COPD groups was compared to the Non-smokers group (set as I) and that in CSE treatment groups was compared to the control group (set as I). (E) The relationship between circ-HACEI and miR-485-3p was analyzed via Pearson's correlation coefficient. (F) The overexpressed efficiency of circ-HACEI vector was evaluated by qRT-PCR in $2 \%$ CSE-treated 16HBE cells. Circ-HACEI expression in CSE, CSE+Vector or CSE+circ-HACEI group was compared to control group (set as I). (G) The effects on si-circ-HACEI or circHACEI on miR-485-3p level were analyzed through qRT-PCR in $2 \%$ CSE-treated I6HBE cells. The level of miR-485-3p in treatment groups was compared to control group (set as I). *P $<0.05$, **P $<0.01$, *** $2<0.001$, ***** $<0.0001$.

expression was upregulated by knockdown of circ-HACE1 while decreased by overexpression of circ-HACE1 (Figure $3 \mathrm{G})$. Circ-HACE1 can negatively regulate miR-485-3p as a molecular sponge.

\section{CSE-Mediated Injury in I6HBE Cells Was Regulated by the Circ-HACEI/miR-485- $3 p$ Axis}

Transfection of anti-miR-485-3p abolished the si-circHACE1-induced miR-485-3p upregulation in CSE-treated $16 \mathrm{HBE}$ cells, indicating that the inhibitory efficiency of anti-miR-485-3p was great (Figure 4A). We further investigated the relation of miR-485-3p with circ-HACE1 in regulating cell injury. The results manifested that the introduction of anti-miR-485-3p in CSE-treated 16HBE cells mitigated the cell viability enhancement (Figure 4B), apoptosis inhibition (Figure 4C-D), cell cycle promotion (Figure 4E), inflammatory response (Figure 4F-G) and oxidative stress (Figure 4H-I) retardment evoked by sicirc-HACE1. Thus, the circ-HACE1/miR-485-3p axis could regulate $16 \mathrm{HBE}$ cell injury by $\mathrm{CSE}$.

\section{TLR4 Acted as a Target of miR-485-3p}

Online Targetscan predicted that TLR4 3'UTR sequence was able to bind to miR-485-3p (Figure 5A). The overexpression of miR-485-3p was also exhibited to reduce the relative 

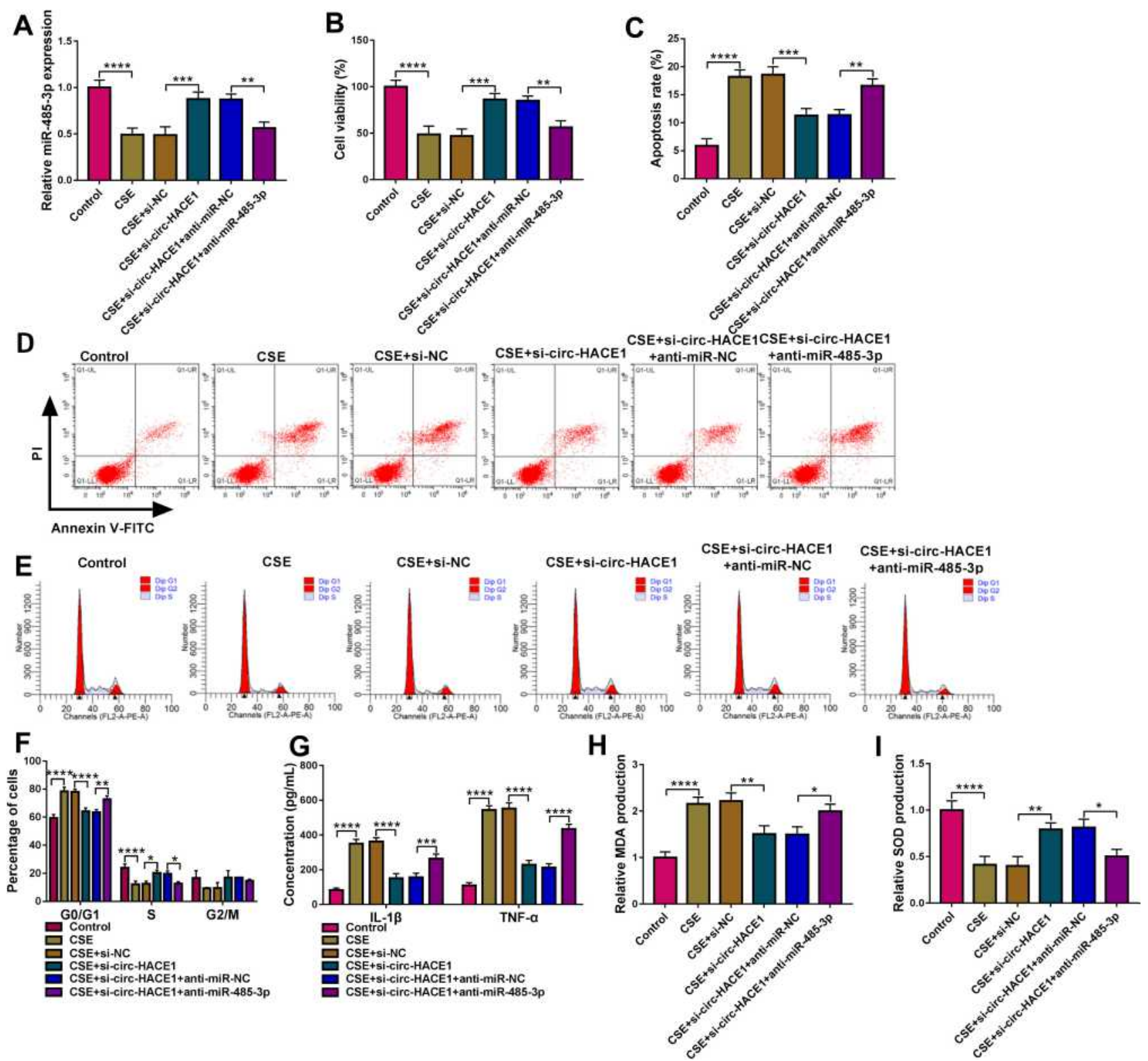

Figure 4 CSE-mediated injury in I6HBE cells was regulated by the circ-HACEI/miR-485-3p axis. $16 \mathrm{HBE}$ cells were treated with $2 \%$ CSE, $2 \%$ CSE+si-NC, $2 \%$ CSE+si-circHACEI, $2 \%$ CSE+si-circ-HACEI+anti-miR-NC or $2 \%$ CSE+si-circ-HACEI+anti-miR-485-3p, and untreated I6HBE cells were used as the control group. (A) The miR-485-3p level was detected applying with qRT-PCR, and miR-485-3p expression in each treatment group was contrasted with control group (set as I). (B) Cell viability was examined by CCK-8 assay. (C-E) Cell apoptosis (C and $\mathbf{D})$ and cell cycle progression (E) were analyzed via flow cytometry. (F and $\mathbf{G})$ Inflammatory response was assessed through the concentrations of IL-I $\beta$ and TNF- $\alpha$. (H and I) Oxidative stress was evaluated by the levels of MDA (H) and SOD (I). The relative production of MDA or SOD in each treatment group was compared to the control group (set as I). $* p<0.05$, **P $<0.01$, $* * * p<0.00 \mathrm{I}$, ****p<0.000I.

luciferase activity in 16HBE cells transfected with TLR4 3'UTR-WT while luciferase activity in cells transfected with TLR4 3'UTR-MUT was not obviously changed (Figure 5B). The qRT-PCR presented the high expression of TLR4 mRNA in serum samples from smokers or smokers with COPD (relative to Non-smokers) (Figure 5C) and there was also a negative correlation $(r=-0.7223, p<0.001)$ between miR-485-3p and TLR4 mRNA expression (Figure 5D). The same overexpression was found in TLR4 protein level after
CSE treatment in 16HBE cells (Figure 5E). After 16HBE cells were exposed to CSE, transfection of miR-NC, miR485-3p, anti-miR-NC or anti-miR-485-3p was performed. The transfection efficiencies of miR-485-3p for overexpression and anti-miR-485-3p for inhibition on miR-485-3p expression were excellent through qRT-PCR analysis (Figure 5F). TLR4 protein expression inhibition by miR485-3p and promotion by anti-miR-485-3p in CSE-treated 16HBE cells indicated the negative effect of miR-485-3p on 


\section{A

\begin{tabular}{|l}
$\begin{array}{ll}\text { TLR4 3'UTR-WT 5' AGUAUGCUUGAAAAUGUAUGAU 3' } \\
\text { miR-485-3p } & \text { 3' UCUCUCCUCUCGGCACAUACUG 5' } \\
\text { TLR4 3'UTR-MUT 5' AGUAUGCUUGAAAAACAUACUU 3' }\end{array}$ \\
\hline
\end{tabular}

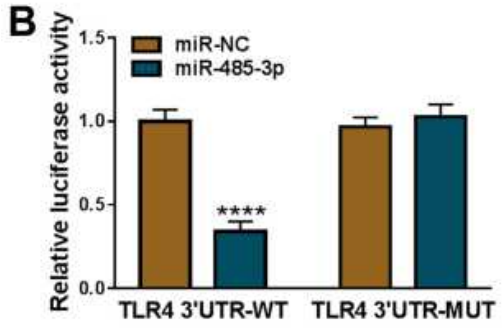

C
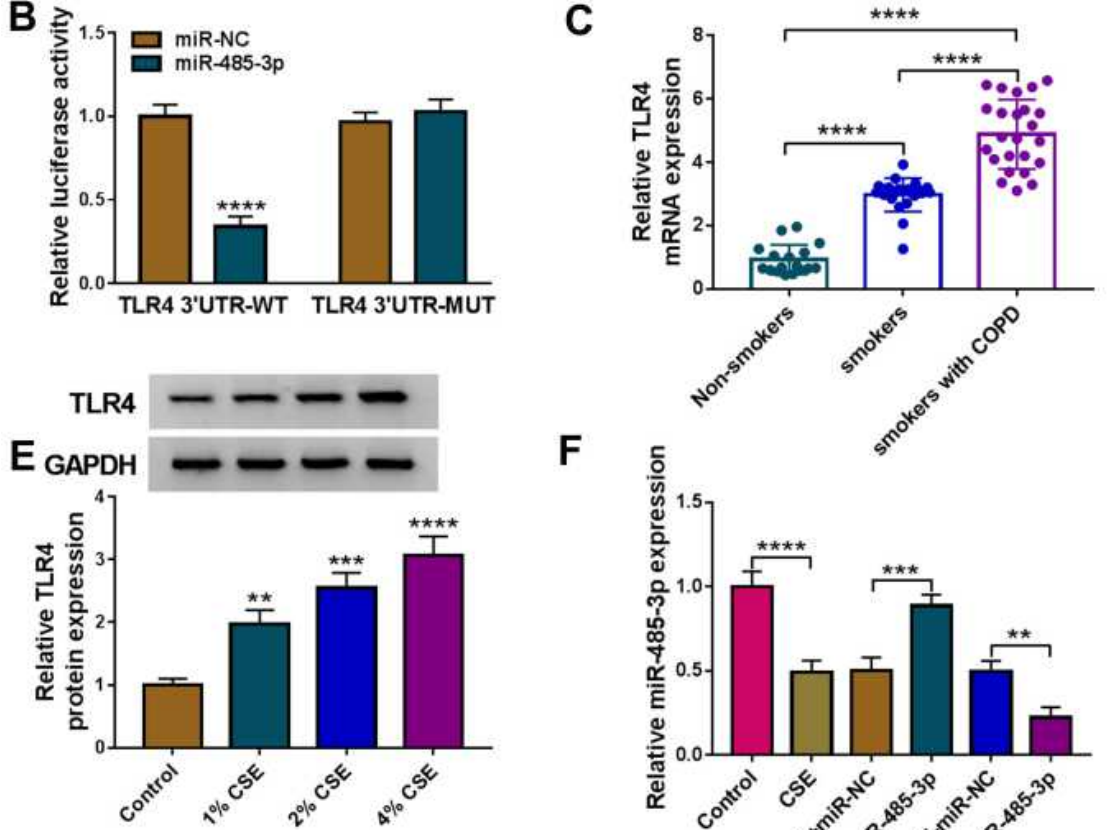

$\mathbf{F}$

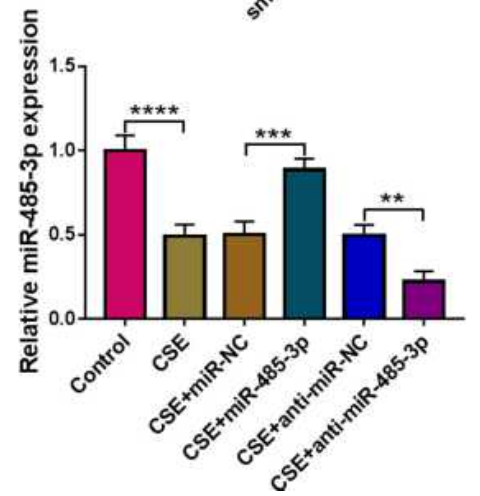

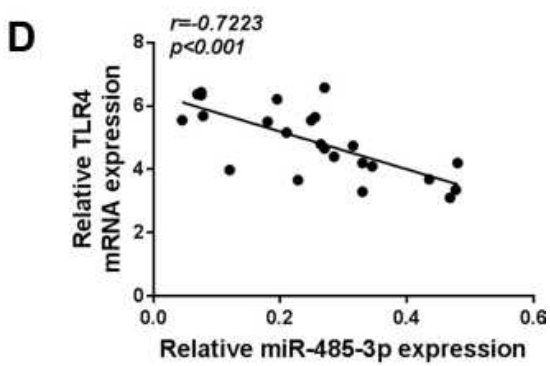

G

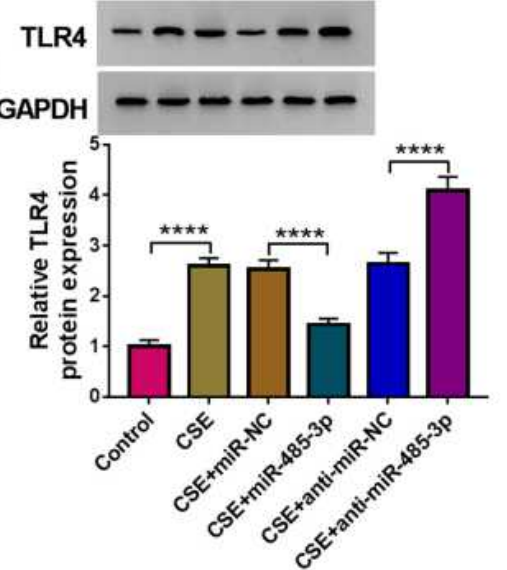

Figure 5 TLR4 acted as a target of miR-485-3p. (A) The binding sites of miR-485-3p in the 3'UTR of TLR4 were predicted by Targetscan. (B) The interaction between miR485-3p and TLR4 3'UTR was proved by dual-luciferase reporter assay. (C) TLR4 mRNA expression was assayed by qRT-PCR in serum samples, and the expression in smoker or smoker with COPD group was compared to the Non-smoker group (set as I). (D) Pearson's correlation coefficient was used for linear analysis between miR-485-3p and TLR4. (E) Western blot was performed for the protein expression detection of TLR4 in 1\%, 2\% or 4\% CSE-treated I6HBE cells. (F and G) After transfection of miR-485-3p mimic, miR-485-3p inhibitor or the matched controls in $2 \%$ CSE-treated $16 \mathrm{HBE}$ cells, the miR-485-3p level (F) and TLR4 protein expression (G) were respectively determined via qRT-PCR and Western blot. The level in control group was set as I, and that in other each group was compared with the control group. $* * P<0.0 \mathrm{I}$, ***P $<$ 0.001 , $* * * * P<0.0001$.

the level of TLR4 (Figure 5G). TLR4 was a target gene in the downstream of miR-485-3p.

\section{MiR-485-3p Delayed the CSE-Induced Cell Damage via Downregulating TLR4}

The functional mechanism between miR-485-3p and TLR4 was researched in CSE-treated $16 \mathrm{HBE}$ cells transfected with miR-NC, miR-485-3p, miR-485-3p+pcDNA or miR-485-3p +TLR4. Western blot has revealed that the TLR4 protein expression inhibition caused by miR-485-3p was reversed after transfection of TLR4 (Figure 6A). Cellular experiments indicated that transfection of TLR4 partly abrogated the miR-485-3p-mediated cell viability promotion (Figure 6B) cell apoptosis inhibition (Figure 6C-D) and cell cycle acceleration (Figure 6E) in CSE-treated 16HBE cells. As for inflammation and oxidative stress, the overexpression of
TLR4 also lightened the miR-485-3p-induced concentration decline of IL-1 $\beta$ and TNF- $\alpha$ (Figure 6F-G), as well as MDA downregulation and SOD elevation (Figure 6H-I). MiR-485$3 p$ inhibited the cell damage by CSE via targeting TLR4.

\section{Knockdown of Circ-HACEI Regulated Cell Injury by Upregulating miR-485-3p to Decrease TLR4 Expression in CSE-Treated I6HBE Cells}

The potential expression regulation between circ-HACE1 and TLR4 was further studied. TLR4 mRNA (Figure 7A) and protein (Figure 7B) levels were suppressed in CSE+si-circHACE1 group compared to CSE group in 16HBE cells, whereas TLR4 expression suppression by si-circ-HACE1 was subsequently alleviated following the anti-miR-485-3p 

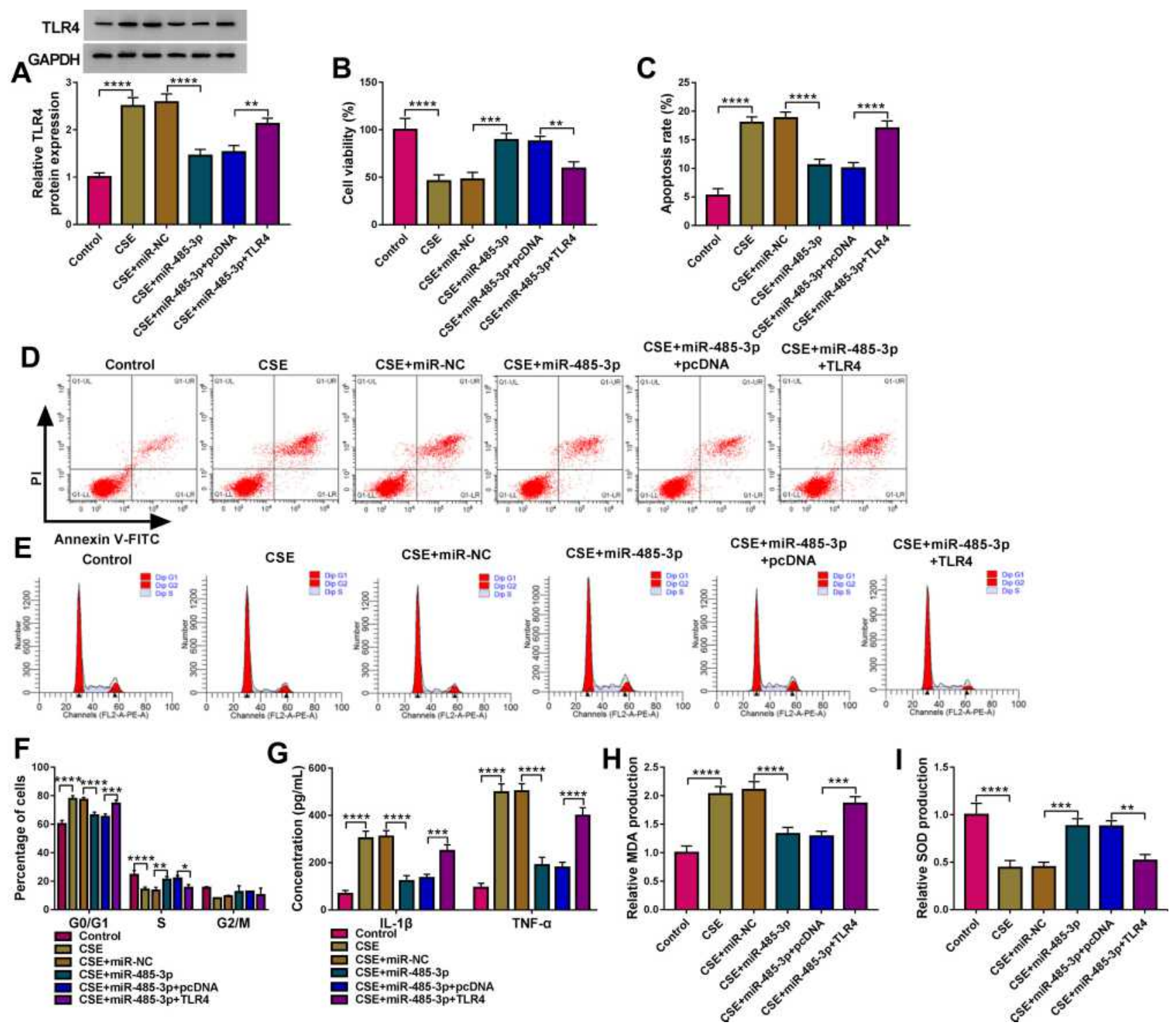

Figure 6 miR-485-3p delayed the CSE-induced cell damage via downregulating TLR4. Transfection of miR-485-3p, miR-485-3p+TLR4 or the corresponding controls was performed in 2\% CSE-treated I6HBE cells. (A) The protein level of TLR4 was detected using Western blot. (B-E) The examination of cell viability (B) and apoptosis (C and D)/cell cycle (E) was completed by respective CCK-8 and flow cytometry. (F and G) The assessment of inflammation was conducted by measuring the concentrations of ILI $\beta$ and TNF- $\alpha$. (H and I) MDA (H) and SOD (I) levels were used for the evaluation of oxidative injury. The relative production of MDA or SOD in each treatment group was compared to the control group (set as I). $* P<0.05$, **P $<0.0$ I, $* * * P<0.00$ I, $* * * * P<0.000$ I.

transfection. The expression analysis suggested that knockdown of circ-HACE1 downregulated the level of TLR4 by increasing miR-485-3p expression. To further investigate whether the function of circ-HACE1 was associated with the miR-485-3p-mediated TLR4 expression change, we have performed the reverted transfection (si-NC, si-circ-HACE1, siHACE1+pcDNA, si-circ-HACE1+TLR4) after 16HBE cells were treated with $2 \% \mathrm{CSE}$. The results have demonstrated that the introduction of TLR4 relived all those effects of si-circHACE1 on biological behaviors of CSE-treated 16HBE cells (Supplementary Figure 2). Overall, the circ-HACE1 function was ascribed to the regulation of miR-485-3p-mediated TLR4 as least in part.

\section{Discussion}

In this report, we affirmed that the dysregulation of circHACE1, miR-485-3p and TLR4 was associated with the CSEinduced COPD. Circ-HACE1 downregulation ameliorated the bronchial epithelial cell injury caused by CSE via targeting miR-485-3p to regulate TLR4 expression level.

Dysregulated circRNAs are usually related to the progression of human respiratory diseases. ${ }^{19}$ Blood circRNAs have been suggested as reliable targets for the diagnosis of active pulmonary tuberculosis. ${ }^{20} \mathrm{Li}$ et al found 67 dysregulated circRNAs in idiopathic pulmonary fibrosis via a circRNA microarray and clarified the circRNA/ 


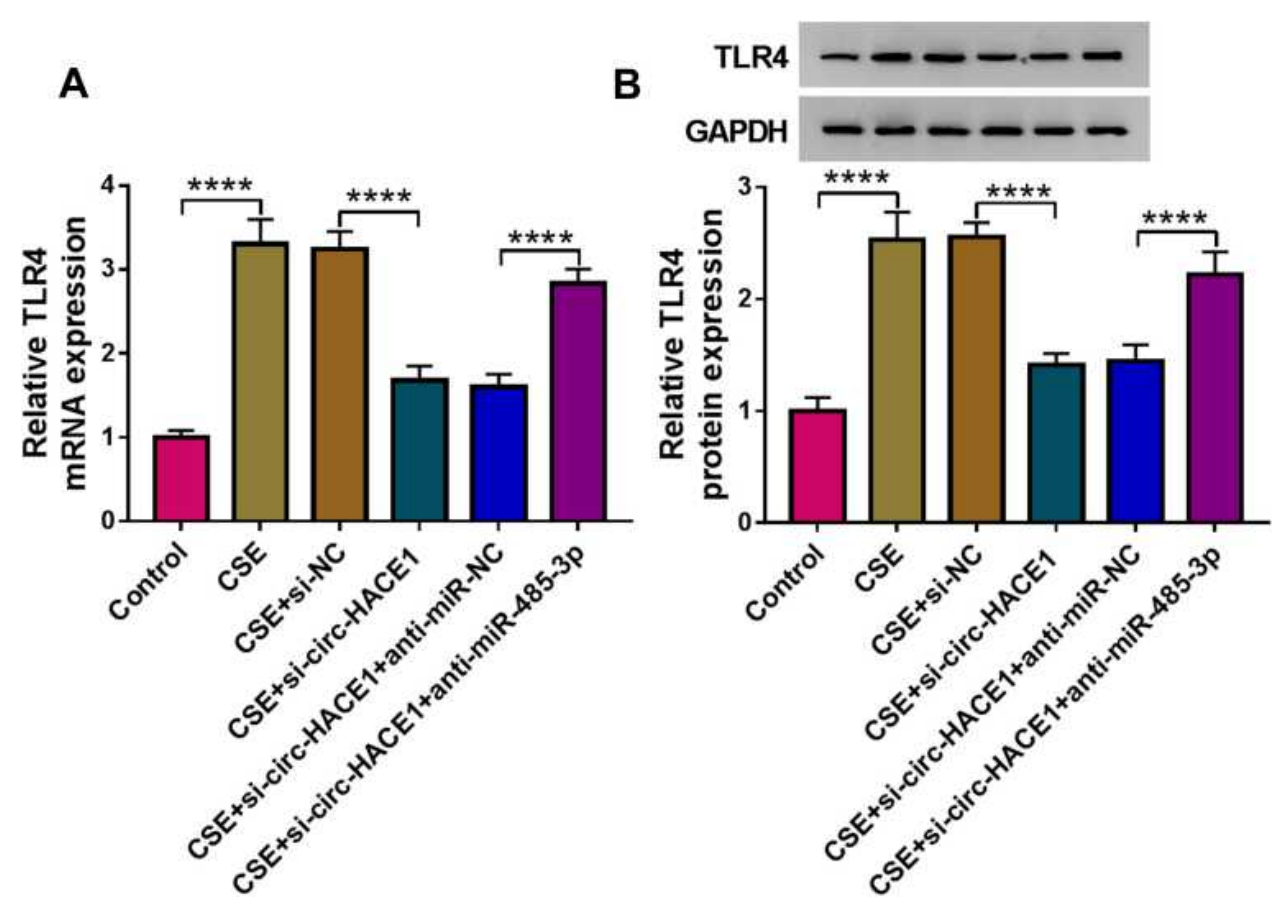

Figure 7 Knockdown of circ-HACEI upregulated miR-485-3p to decrease TLR4 expression in CSE-treated I6HBE cells. (A and B) The qRT-PCR and Western blot were exploited for the measurement of TLR4 mRNA (A) and protein (B) in $2 \%$ CSE-treated I6HBE cells transfected with si-NC, si-circ-HACEI, si-circ-HACEI+anti-miR-NC or si-circ-HACEI+anti-miR-485-3p, with untreated cells as the control group. TLR4 expression in each treatment group was compared with the control group (set as I). $* * * * P<0.0001$.

miRNA/mRNA network. ${ }^{21}$ Lin et al exhibited that circHIPK3 contributed to proliferation and migration of airway smooth muscle cells in the development of asthma via the miR-326/STIM1 axis. ${ }^{22}$ The researches of COPD have revealed that circBbs9 enhanced lung inflammation via targeting the miR-30e-5p/Adar pathway, ${ }^{23}$ and hsa_circRNA_0008672 promoted the pathogenesis of COPD via acting on the miR-1265/MAPK1 axis. ${ }^{24}$

Herein, circ-HACE1 expression was significantly increased in smokers or smokers with COPD compared to non-smokers and $16 \mathrm{HBE}$ cells treated with CSE contrasted with the untreated cells. Thus, circ-HACE1 upregulation might be one of the molecular manifestations of COPD occurrence. Circ-HACE1 could be used as a biomarker to improve the clinical diagnosis of COPD. Cellular experiments demonstrated that CSE stimulation triggered the inhibitory effects on cell viability and cell cycle progression but promotive effects on apoptosis and inflammation. Interestingly, knockdown of circ-HACE1 has reverted these effects in $16 \mathrm{HBE}$ cells. In addition to primary inflammation, oxidative stress can induce mitochondrial dysfunction to further drive lung inflammation in COPD. ${ }^{25}$ Through the detection of MDA and SOD, we found the downregulation of circ-HACE1 relieved the oxidative stress evoked by CSE. These results identified that downregulating circ-HACE1 ameliorated the CSEinduced cell damages, indicating that the knockdown of circ-HACE1 could be used a therapeutic strategy to inhibit the progression of COPD in clinic. This molecular therapy may be beneficial for the treatment of COPD, and further research in clinical presentation needs to be performed.

To explore the potential circRNA/miRNA/mRNA axis underpinning circ-HACE1, Circinteractome software was used to seek the miRNA target of circ-HACE1. MiR-485$3 \mathrm{p}$ was shown to interact with circ-HACE1 and circHACE1 acted as a sponge to negatively regulate the miR-485-3p expression. The level of miR-485-3p was lower in smokers and smokers with COPD than that in non-smokers, and its expression was also reduced by CSE in $16 \mathrm{HBE}$ cells. Furthermore, the alleviation of si-circHACE1 on the CSE-stimulated cell injury was blocked by miR-485-3p inhibition. Circ-HACE1 was firstly identified as a miRNA sponge, and circ-HACE1/miR-485-3p axis was confirmed to be implicated in the pathological development of COPD in vitro. Regulating target gene expression is the most common functional mechanism of miRNAs. In COPD, miR-206 facilitated cell apoptosis in human pulmonary microvascular endothelial cells by the direct regulation of Notch 3 and VEGFA; ${ }^{26}$ miR-664a-3p 
overexpression was accountable for CSE-induced COPD through inhibiting FHL1. ${ }^{27}$ Tang et al declared that miR$29 \mathrm{~b}$ downregulation participated in the airway inflammation via upregulating BRD4. ${ }^{28}$ In this chapter, miR-485-3p was discovered to have target relation with TLR4. TLR4 was highly expressed in smokers and smokers with COPD relative to non-smokers, as well as in CSE-treated $16 \mathrm{HBE}$ cells relative to control cells. MiR-485-3p played a protective role for $16 \mathrm{HBE}$ cells against CSE via downregulating the expression of TLR4, which also suggested that TLR4 acted as a pathogenic gene in CSE-induced COPD. The miR-485-3p/TLR4 signal axis was also disclosed in the COPD research for the first time. More importantly, we found that circ-HACE1 knockdown reduced the expression of TLR4 via miR-485-3p. Meanwhile, the overexpression of TLR4 eliminated the alleviation of circ-HACE1 siRNA on CSE-induced cell damages. TLR4 was again affirmed to promote the CSEinduced COPD progression, and the promoting effect of circ-HACE1 on CSE-induced COPD was also attributed to the TLR4 upregulation. Our results have clearly clarified how circ-HACE1 acted in the developing process of CSEinduced COPD. The discovery of circ-HACE1/miR-485$3 \mathrm{p} /$ TLR4 axis could contribute to the understanding of molecular mechanism in COPD progression.

TLR4 is associated with the inflammatory response in some diseases. Downregulation of circ_0068087 impeded the high glucose-induced cell dysfunction and inflammation in diabetes mellitus via targeting miR-197 to regulate TLR4. ${ }^{29}$ CircLRP6 regulated inflammation and oxidative stress in diabetic nephropathy via the miR-205/TLR4 axis. ${ }^{30}$ CircTUBD1 acted as a pro-inflammatory factor in radiation-induced liver disease by modulating TLR4 as the miR-146a-5p sponge. ${ }^{31}$ Our findings exhibited that the miR-485-3p/TLR4 axis was partly responsible for the function of circ-HACE1 in CSEinduced COPD. Overall, we have provided the first information for the function of mechanism of circ-HACE1 in COPD.

In conclusion, knockdown of circ-HACE1 suppressed CSE-triggered apoptosis, inflammation and oxidative stress in $16 \mathrm{HBE}$ cells via the miR-485-3p/TLR4 axis. The diagnostic efficiency of COPD can be enhanced using circ-HACE1 as a molecular target, and the therapeutic management of COPD may also be improved through the expression inhibition of circ-HACE1.

\section{Abbreviations}

COPD, chronic obstructive pulmonary disease; Circ-HACE1, CircRNA HECT domain and ankyrin repeat containing E3 ubiquitin protein ligase 1; TLR4, toll-like receptor 4; CSE, cigarette smoke extract; HBE, human bronchial epithelial cells; qRT-PCR, quantitative real-time polymerase chain reaction; GAPDH, glyceraldehyde-phosphate dehydrogenase; CCK-8, cell counting kit-8; FITC, fluorescein isothiocyanate; PI, propidium iodide; ELISA, enzyme-linked immunosorbent assay; IL-1 $\beta$, interleukin-1beta; TNF- $\alpha$, tumor necrosis factoralpha; MDA, malondialdehyde; SOD, superoxide dismutase; 3'-UTR, 3'-untranslated region.

\section{Data Sharing Statement}

Please contact the correspondence author for the data request.

\section{Ethics Approval and Consent Participate}

Written informed consent was obtained from patients with approval by the Institutional Review Board in 4th Affiliated Hospital of Anhui Medical University.

\section{Funding}

This work was supported by key research projects of natural science in colleges and universities of Anhui province (KJ2018A0858).

\section{Disclosure}

The authors declare that they have no financial or other conflicts of interest.

\section{References}

1. Moon J-Y, Leitao Filho FS, Shahangian K, et al. Blood and sputum protein biomarkers for chronic obstructive pulmonary disease (COPD). Expert Rev Proteomics. 2018;15(11):923-935. doi:10.1080/ 14789450.2018.1539670

2. Eapen MS, Myers S, Walters EH, et al. Airway inflammation in chronic obstructive pulmonary disease (COPD): a true paradox. Expert Rev Respir Med. 2017;11:827-839. doi:10.1080/ 17476348.2017.1360769

3. Hikichi M, Mizumura K, Maruoka S, et al. Pathogenesis of chronic obstructive pulmonary disease (COPD) induced by cigarette smoke. J Thorac Dis. 2019;11:S2129-S2140. doi:10.21037/jtd.2019.10.43

4. Sun Y, Zhou J. New insights into early intervention of chronic obstructive pulmonary disease with mild airflow limitation. Int $J$ Chron Obstruct Pulmon Dis. 2019;14:1119-1125. doi:10.2147/COPD. S205382

5. Mei D, Tan WSD, Tay Y, et al. Therapeutic RNA strategies for chronic obstructive pulmonary disease. Trends Pharmacol Sci. 2020;41:475-486. doi:10.1016/j.tips.2020.04.007

6. Han B, Chao J, Yao H. Circular RNA and its mechanisms in disease: from the bench to the clinic. Pharmacol Ther. 2018;187:31-44. doi:10.1016/j.pharmthera.2018.01.010 
7. Zhang C, Huo ST, Wu Z, et al. Rapid development of targeting circRNAs in cardiovascular diseases. Mol Ther Nucleic Acids. 2020;21:568-576. doi:10.1016/j.omtn.2020.06.022

8. Azari H, Mousavi P, Karimi E, et al. The expanding role of CDR1-AS in the regulation and development of cancer and human diseases. J Cell Physiol. 2020. doi:10.1002/jcp.29950

9. Zeng N, Wang T, Chen M, et al. Cigarette smoke extract alters genome-wide profiles of circular RNAs and mRNAs in primary human small airway epithelial cells. $J$ Cell Mol Med. 2019;23:5532-5541. doi:10.1111/jcmm.14436

10. Huang $X, Z$ Zhu Z, Guo X, et al. The roles of microRNAs in the pathogenesis of chronic obstructive pulmonary disease. Int Immunopharmacol. 2019;67:335-347. doi:10.1016/j. intimp.2018.12.013

11. Mohamed A, Kunda NK, Ross K, et al. Polymeric nanoparticles for the delivery of miRNA to treat Chronic Obstructive Pulmonary Disease (COPD). Eur J Pharm Biopharm. 2019;136:1-8. doi:10.1016/j.ejpb.2019.01.002

12. Li X, Yu X, He Y, et al. Integrated analysis of MicroRNA (miRNA) and mRNA profiles reveals reduced correlation between microRNA and target gene in cancer. Biomed Res Int. 2018;2018:1972606. doi:10.1155/2018/1972606

13. Musri MM, Coll-Bonfill N, Maron BA, et al. MicroRNA dysregulation in pulmonary arteries from chronic obstructive pulmonary disease. relationships with vascular remodeling. Am J Respir Cell Mol Biol. 2018;59:490-499. doi:10.1165/rcmb.2017-0040OC

14. Shen W, Liu J, Zhao G, et al. Repression of Toll-like receptor-4 by microRNA-149-3p is associated with smoking-related COPD. Int J Chron Obstruct Pulmon Dis. 2017;12:705-715. doi:10.2147/ COPD.S128031

15. Jia R, Zhao XF. MicroRNA-497 functions as an inflammatory suppressor via targeting DDX3Y and modulating toll-like receptor 4/ NF-kappaB in cigarette smoke extract-stimulated human bronchial epithelial cells. J Gene Med. 2020;22:e3137. doi:10.1002/jgm.3137

16. Song J, Wang Q, Zong L. LncRNA MIR155HG contributes to smoke-related chronic obstructive pulmonary disease by targeting miR-128-5p/BRD4 axis. Biosci Rep. 2020;40:BSR20192567. doi:10.1042/BSR20192567

17. Maurya PK, Noto C, Rizzo LB, et al. The role of oxidative and nitrosative stress in accelerated aging and major depressive disorder. Prog Neuropsychopharmacol Biol Psychiatry. 2016;65:134-144. doi:10.1016/j.pnpbp.2015.08.016

18. Zhou Q, Zhu L, Zhang D, et al. Oxidative stress-related biomarkers in postmenopausal osteoporosis: a systematic review and meta-analyses. Dis Markers. 2016;2016:7067984. doi:10.1155/2016/ 7067984

19. Wang J, Zhu M, Pan J, et al. Circular RNAs: a rising star in respiratory diseases. Respir Res. 2019;20:3. doi:10.1186/s12931018-0962-1
20. Qian Z, Liu H, Li M, et al. Potential diagnostic power of blood circular RNA expression in active pulmonary tuberculosis. EBioMedicine. 2018;27:18-26. doi:10.1016/j.ebiom.2017.12.007

21. Li R, Wang Y, Song X, et al. Potential regulatory role of circular RNA in idiopathic pulmonary fibrosis. Int $J$ Mol Med. 2018;42:3256-3268. doi:10.3892/ijmm.2018.3892

22. Lin J, Feng X, Zhang J. Circular RNA circHIPK3 modulates the proliferation of airway smooth muscle cells by miR-326/STIM1 axis. Life Sci. 2020;255:117835. doi:10.1016/j.lfs.2020.117835

23. Li M, Hua Q, Shao Y, et al. Circular RNA circBbs9 promotes PM2.5-induced lung inflammation in mice via NLRP3 inflammasome activation. Environ Int. 2020;143:105976. doi:10.1016/j. envint.2020.105976

24. Duan R, Niu H, Yu T, et al. Identification and bioinformatic analysis of circular RNA expression in peripheral blood mononuclear cells from patients with chronic obstructive pulmonary disease. Int $J$ Chron Obstruct Pulmon Dis. 2020;15:1391-1401. doi:10.2147/COPD.S252896

25. Wiegman $\mathrm{CH}$, Michaeloudes $\mathrm{C}$, Haji $\mathrm{G}$, et al. Oxidative stress-induced mitochondrial dysfunction drives inflammation and airway smooth muscle remodeling in patients with chronic obstructive pulmonary disease. J Allergy Clin Immunol. 2015;136:769-780. doi:10.1016/j.jaci.2015.01.046

26. Sun Y, An N, Li J, et al. miRNA-206 regulates human pulmonary microvascular endothelial cell apoptosis via targeting in chronic obstructive pulmonary disease. $J$ Cell Biochem. 2019;120:6223-6236. doi:10.1002/jcb.27910

27. Zhong S, Chen C, Liu N, et al. Overexpression of hsa-miR-664a-3p is associated with cigarette smoke-induced chronic obstructive pulmonary disease via targeting FHL1. Int J Chron Obstruct Pulmon Dis. 2019;14:2319-2329. doi:10.2147/COPD.S224763

28. Tang K, Zhao J, Xie J, et al. Decreased miR-29b expression is associated with airway inflammation in chronic obstructive pulmonary disease. Am J Physiol Lung Cell Mol Physiol. 2019;316:L621L629. doi:10.1152/ajplung.00436.2018

29. Cheng J, Liu Q, Hu N, et al. Downregulation of hsa circ 0068087 ameliorates TLR4/NF-kappaB/NLRP3 inflammasome-mediated inflammation and endothelial cell dysfunction in high glucose conditioned by sponging miR-197. Gene. 2019;709:1-7. doi:10.1016/j. gene.2019.05.012

30. Chen B, Li Y, Liu Y, et al. circLRP6 regulates high glucose-induced proliferation, oxidative stress, ECM accumulation, and inflammation in mesangial cells. $J$ Cell Physiol. 2019;234:21249-21259. doi: $10.1002 /$ jcp. 28730

31. Niu H, Zhang L, Chen YH, et al. Circular RNA TUBD1 acts as the miR-146a-5p sponge to affect the viability and pro-inflammatory cytokine production of LX-2 cells through the TLR4 pathway. Radiat Res. 2020;193:383-393. doi:10.1667/RR15550.1

\section{Publish your work in this journal}

The International Journal of COPD is an international, peer-reviewed journal of therapeutics and pharmacology focusing on concise rapid reporting of clinical studies and reviews in COPD. Special focus is given to the pathophysiological processes underlying the disease, intervention programs, patient focused education, and self management protocols. This journal is indexed on PubMed Central, MedLine and CAS. The manuscript management system is completely online and includes a very quick and fair peer-review system, which is all easy to use. Visit http://www.dovepress.com/testimonials.php to read real quotes from published authors. 